\title{
Identification of the principal elements governing the wettability characteristics of ordinary Portland cement following high power diode laser surface treatment
}

\author{
J. Lawrence \\ Manufacturing Engineering Division, School of Mechanical \& Production Engineering, Nanyang \\ Technological University (NTU), Nanyang Avenue, Singapore 639798.
}

\section{Correspondence}

Dr. Jonathan Lawrence,

Manufacturing Engineering Division,

School of Mechanical \& Production Engineering,

Nanyang Technological University (NTU),

Nanyang Avenue,

Singapore 639798.

Tel : (65) 67905542

Fax : (65) 67911859

e-mail: mjlawrence@ntu.edu.sg 


\begin{abstract}
The elements governing modifications to the wettability characteristics of ordinary Portland cement (OPC) following high power diode laser (HPDL) surface treatment have been identified. Changes in the contact angle, $\theta$, and hence the wettability characteristics of the OPC after HPDL treatment were attributed to: reductions in the surface roughness of the OPC; the increase in the surface $\mathrm{O}_{2}$ content of the ceramic and the increase in the polar component of the surface energy, $\gamma_{s v}^{p}$. What is more, the degree of influence exerted by each element has been qualitatively ascertained and was found to differ markedly. Surface energy, by way of microstructural changes, was found to be by far the most predominant element governing the wetting characteristics of the OPC. To a much lesser extent, surface $\mathrm{O}_{2}$ content, by way of process gas, was also seen to influence to a changes in the wettability characteristics of the OPC, whilst surface roughness was found to play a minor role in inducing changes in the wettability characteristics.
\end{abstract}

Keywords: Ordinary Portland cement (OPC); High power diode laser (HPDL); Glazing; Contact angle; Wettability; Surface energy 


\section{Introduction}

Increasingly within the fields of science and engineering, the unique characteristics of lasers are being recognised. One such characteristic is the laser's ability to be employed for the non-contact processing of materials which are otherwise difficult to process, such as ordinary Portland cement (OPC) and concrete. Despite the considerable amount of work that has been carried out previously to investigate the laser processing of OPC and concrete, most has concentrated on the laser cutting of concrete and reinforced concrete using high power $\mathrm{CO}_{2}$ lasers [1-3] and the direct glazing, single and multiple layer fusion cladding and combined chemical/fusion cladding for the sealing/fixing of radioactive contamination onto concrete surfaces [4-7]. More recent work by Johnston et al. [8] reported on the successful removal of the contaminated surface layer of concrete (scabbling) by means of Nd:YAG and $\mathrm{CO}_{2}$ laser radiation. Work by Sugimoto et al. [9] focused upon modifying the surface appearance and surface properties of cement based materials using a high power $\mathrm{CO}_{2}$ laser. The resultant physical characteristics and mechanical behaviour of the post-process cement based materials were later fully characterised by Wignarajah et al. [10]. Borodina et al. [11] have carried out investigations into the structural changes within the composition of zirconia concrete caused by surface exposure to $\mathrm{CO}_{2}$ laser radiation, detailing microstructural changes, phase changes and the absorptivity characteristics. In all of the previous studies conducted with $\mathrm{CO}_{2}$ and $\mathrm{Nd}$ :YAG lasers, spallation and excessive cracking and pore formation were found to be major problems undermining the performance of the laser treated surface layer. In contrast, however, work conducted by Li et al. [12] and further work carried out by Lawrence et al. [13-18] using a high power diode laser (HPDL), successfully demonstrated the generation of a long-lasting glaze with far fewer cracks and pores.

There is a burgeoning literature base that testifies to the potential of lasers for altering the surface properties of materials in order to improve their wettability characteristics. The well documented fact that generated oxide layers often promote metal/oxide wetting has been reported by Zhou and DeHosson $[19,20]$ as a result of work on the laser coating of aluminium alloys with ceramic material. Bahners and Bahners et al. [21, 22], have observed and comprehensively detailed the changes in technical properties of various textile fibres, including adhesion and wetting properties, with a view to developing an alternative to the conventional methods of chemical agents addition or wet-chemical pre-processing. In recent years the excimer laser has been employed to precisely control and later the surface characteristics of a number of polymer materials. Ample research has been carried out to study the effects of excimer laser radiation on the wettability characteristics of polyethylene terephthalate (PET) in both film [23], fibre [24] and sheet [25] form, as well as polyparaphenylene terephthalamide (PPTA) [26]. Laurens et al. [27] concluded that a more polar surface resulted from the excimer laser treatment of polyether-etherketon (PEEK). Extensive and detailed investigations by Song and Netravali [29-31] into the effects of excimer laser radiation on the interfacial characteristics of UHSPE fibres and epoxy resin revealed a considerable increase in the interfacial shear strength 
resulted after laser treatment. Furthermore, Heitz et al. [23], Henari and Blau [32] and Olfert et al. [33] have found that excimer laser treatment of metals results in improved coating adhesion.

Still, the reasons for the changes in the wetting characteristics with regard to changes in the material's surface topography, surface composition and surface energy have not been reported on in great deal in any of the previous studies. Having said that, Lawrence and Li have sufficiently demonstrated the practicability of employing different types of lasers to effect changes in the wettability characteristics of ceramics [34-38] metals [39-41] and polymers [42, 43] for improved adhesion and bonding, as well as comprehensively examining the changes in the wettability characteristics of the materials in terms of surface topography, surface composition and surface energy. Moreover, Lawrence and Li [44] have extended knowledge in this field by determining the predominant influential elements involved with the HPDL modification the wettability characteristics of metallic materials, as well as quantifying the degree of influence each element exerts.

This paper aims to extend this preceding work on metallic materials by elucidating and giving a greater understanding of the basic process phenomena and the predominant influential elements involved with the HPDL modification the wettability characteristics of OPC. In particular, the principal elements governing the wettability characteristics, namely morphology, microstructure and surface chemistry, and the individual effects thereof on the HPDL modified wettability characteristics of OPC are identified. This work describes the employment of a number of techniques to isolate these elements, thereby allowing their singular effect on changes to the wettability characteristics of the OPC treated with the HPDL to be established.

\section{Theoretical background of wettability and adhesion}

\subsection{Contact angle}

When a drop of liquid is placed on a solid surface it may remain as a spherical drop, or spread to cover (wet) the solid surface. The angle with which the liquid subtends the solid is known as the contact angle. In practice, for wetting to occur the contact angle is less than $90^{\circ}$. If the contact angle is greater than $90^{\circ}$ then the liquid does not wet the solid and no adhesion occurs [45]. When a drop of liquid is brought into contact with a flat solid surface, the final shape taken by the drop, and thus whether it will wet the surface or not, depends upon the relative magnitudes of the molecular forces that exist within the liquid (cohesive) and between the liquid and the solid (adhesive). The index of this effect is the contact angle, $\theta$, which the liquid subtends with the solid. $\theta$ is related to the solid and liquid surface energies, $\gamma_{s v}$ and $\gamma_{l v}$, and the solid-liquid interfacial energy $\gamma_{\mathrm{s}}$, through the principle of virtual work expressed by the rearranged Young's equation: 


$$
\cos \theta=\frac{\gamma_{s v}-\gamma_{s l}}{\gamma_{l v}}
$$

Clearly, to achieve wetting $\gamma_{\mathrm{sv}}$ should be large, while $\gamma_{\mathrm{sl}}$ and $\gamma_{\mathrm{lv}}$ should be small. Hence liquids of a lower surface tension will always spread over a solid surface of higher surface tension in order to reduce the total free-energy of the system [46]. This is on account of the fact that the molecular adhesion between solid and liquid is greater than the cohesion between the molecules of the liquid [45].

\subsection{Work of adhesion}

In fundamental terms, the driving force for the formation of a metal/ceramic interface is the energy relinquished when the intimate contact between the metal and the ceramic is formed. This driving force is usually characterised by the adhesion energy. The adhesion energy, or work of adhesion, $W_{a d}$, is defined as the work per unit area which needs to be provided to separate reversibly a solid/liquid interface so as to create distinct solid/vapour and liquid/vapour interfaces. Thus

$$
W_{a d}=\gamma_{s v}+\gamma_{l v}-\gamma_{s l}
$$

If one takes into account Young's equation then Eq. (1) can be rearranged to form the Young-Dupre equation. Thus the $W_{a d}$ can be expressed as

$$
W_{a d}=\gamma_{l v}(1+\cos \theta)
$$

In this way experimental values of $W_{a d}$ can be determined from the $\gamma_{\mathrm{lv}}$ value of the liquid and the value of $\theta$ produced when the liquid is in contact with the solid.

Generally the value of $W_{a d}$ in metal/ceramic systems can be expressed as the sum of the different contributions of the interfacial interactions between two phases:

$$
W_{a d}=W_{\text {equil }}+W_{\text {non-equil }}
$$

where $W_{\text {non-equil }}$ denotes the non-equilibrium contribution to the work of adhesion when a chemical reaction takes place at the metal/ceramic interface, while $W_{\text {equil }}$ represents the equilibrium contribution which corresponds to non-reactive systems. This contribution can be further divided into two separate terms: $W_{\text {chem-equil }}$, which is the cohesive energy between the two contacting phases that results from the establishment of chemical equilibrium bonds achieved by the mutual saturation of the free valences of the contacting surfaces and $W_{V D W}$, which signifies the van der Waals interaction or dispersion forces. As such, Eq. 4 becomes

$$
W_{a d}=W_{\text {chem-equil }}+W_{V D W}+W_{\text {non-equil }}
$$




\subsection{Surface energy}

The intermolecular attraction which is responsible for surface energy, $\gamma$, arises from a variety of intermolecular forces whose contribution to the total surface energy is additive. The majority of these forces are functions of the particular chemical nature of a certain material, and as such the total surface energy comprises of $\gamma^{p}$ (polar or non-dispersive interaction) and $\gamma^{d}$ (dispersive component; since van der Waals forces are present in all systems regardless of their chemical nature). Therefore, the surface energy of any system can be described by [45]

$$
\gamma=\gamma^{d}+\gamma^{p}
$$

Likewise, $W_{a d}$ can be expressed as the sum of the different intermolecular forces that act at the interface [45]:

$$
W_{a d}=W_{a d}^{d}+W_{a d}^{p}=2\left(\gamma_{s v}^{d} \gamma_{l v}^{d}\right)^{1 / 2}+2\left(\gamma_{s v}^{p} \gamma_{l v}^{p}\right)^{1 / 2}
$$

where $W_{a d}^{d}$ is the dispersive component of the work of adhesion, $W_{a d}^{p}$ is the polar component of the work of adhesion, $\gamma_{s v}^{d}$ is the dispersive component of the surface energy at the solid-vapour interface, $\gamma_{l v}^{d}$ is the dispersive component of the surface energy at the liquid-vapour interface, $\gamma_{s v}^{p}$ is the polar component of the surface energy at the solid-vapour interface and $\gamma_{l v}^{p}$ is the polar component of the surface energy at the liquid-vapour interface. By equating Eq. (6) with Eq. (2), $\theta$ for solid/liquid systems can be related to the surface energies of the respective liquid and solid by

$$
\cos \theta=\frac{2\left(\gamma_{s v}^{d} \gamma_{l v}^{d}\right)^{1 / 2}+2\left(\gamma_{s v}^{p} \gamma_{l v}^{p}\right)^{1 / 2}}{\gamma_{l v}}-1
$$

According to Fowkes [45], $\gamma_{s v}^{d}$ can be estimated by using Eq. (7) and plotting the graph of $\cos \theta$ against $\left(\gamma_{l v}^{d}\right)^{1 / 2} / \gamma_{l v}$. Hence the value of $\gamma_{s v}^{d}$ is estimated by the gradient $\left(=2\left(\gamma_{s v}^{d}\right)^{1 / 2}\right)$ of the line which connects the origin $(\cos \theta=-1)$ with the intercept point of the straight line $\left(\cos \theta\right.$ against $\left.\left(\gamma_{l v}^{d}\right)^{1 / 2} / \gamma_{\mathrm{lv}}\right)$ correlating the data point with the abscissa at $\cos \theta=1$.

It is not possible to determine $\gamma_{s v}^{p}$ in the same direct fashion as the intercept of the straight line $(\cos \theta$ against $\left.\left(\gamma_{l v}^{d}\right)^{1 / 2} / \gamma_{\mathrm{lv}}\right)$ is at $2\left(\gamma_{s v}^{p} \gamma_{l v}^{p}\right)^{1 / 2} / \gamma_{\mathrm{lv}}$ and as such, only refers to individual control test liquids and not the control test liquid system as a whole. Still, it has been established that the entire amount of the surface energies owing to dispersion forces of either the solids or the liquids are active in the wettability performance $[45,47]$. It is therefore possible to calculate $W_{a d}^{d}$ by using only the relevant part of Eq. (6) thus 


$$
W_{a d}^{d}=2\left(\gamma_{s v}^{d} \gamma_{l v}^{d}\right)
$$

Now, if one plots a graph of $W_{a d}$ against $W_{a d}^{d}$ for the solid substrate, then for each particular control test liquid in a given system in contact with the solid substrate surface, $W_{a d}$ (which can be determined from Eq. (3)) can usually be correlated with $W_{a d}^{d}$ by a linear relationship which satisfies

$$
W_{a d}=a W_{a d}^{d}+b
$$

For a solid substrate the constants $a$ and $b$ can be deduced respectively by calculating the gradient of the best-fit straight line and by extrapolating the best-fit straight line to find the axis intercept. Also, if one plots a graph of $\gamma_{l v}^{p}$ against $\gamma_{l v}^{d}$, then for the control test liquids in a given control test liquid system, $\gamma_{l v}^{p}$ can often be correlated with $\gamma_{l v}^{d}$ by a linear relationship which satisfies

$$
\left(\gamma_{l v}^{p}\right)^{1 / 2}=c\left(\gamma_{l v}^{d}\right)^{1 / 2}+d
$$

Again, for a solid substrate the constants $c$ and $d$ can be deduced respectively by calculating the gradient of the best-fit straight line and by extrapolating the best-fit straight line to find the axis intercept. By introducing Eq. (9) into Eq. (6) and rearranging, then

$$
W_{a d}^{p}=(a-1) W_{a d}^{d}+b
$$

or alternatively

$$
\left(\gamma_{s v}^{p}\right)^{1 / 2}\left(\gamma_{l v}^{p}\right)^{1 / 2}=(a-1)\left(\gamma_{s v}^{d}\right)^{1 / 2}\left(\gamma_{l v}^{d}\right)^{1 / 2}+\frac{b}{2}
$$

Further, by introducing Eq. (10) into Eq. (12) and differentiating with respect to $\left(\gamma_{l v}^{d}\right)^{1 / 2}$, considering that $\left(\gamma_{s v}^{d}\right)^{1 / 2}$ and $\left(\gamma_{s v}^{p}\right)^{1 / 2}$ are constant, then the following is valid:

$$
\left(\gamma_{s v}^{p}\right)^{1 / 2}=\frac{\left(\gamma_{s v}^{d}\right)^{1 / 2}(a-1)}{c}
$$

Since $\gamma_{s v}^{d}$ has already been determined from the plot based on Eq. (7), it is possible to calculate $\gamma_{s v}^{p}$ for the solid substrate using Eq. (13). By employing this approach it is possible to determine, from $\theta$ measurements and the control test liquid surface energy properties, the changes in the wettability characteristics effected by HPDL treatment of the OPC. 


\section{Experimental procedures}

\subsection{Materials}

The OPC used in this work was the naturally occurring layer that forms on the outer surfaces of concrete following casting. In this instance, to facilitate the simple execution of the experiments, asreceived concrete blocks were sectioned into squares $\left(120 \times 120 \times 20 \mathrm{~mm}^{3}\right)$ prior to HPDL treatment. The composition by volume of the OPC is as follows: $\mathrm{CaO}(63.9 \%), \mathrm{SiO}_{2}(21.9 \%), \mathrm{Al}_{2} \mathrm{O}_{3}(5.7 \%)$, $\mathrm{Fe}_{2} \mathrm{O}_{3}(2.8 \%), \mathrm{SO}_{3}(2.7 \%), \mathrm{MgO}(2.2 \%), \mathrm{K}_{2} \mathrm{O}(0.7 \%)$ and $\mathrm{Na}_{2} \mathrm{O}(0.1 \%)$, whilst the concrete blocks themselves had a composition by volume of: $20 \mathrm{~mm}$ limestone aggregate (40\%); $10 \mathrm{~mm}$ limestone aggregate (14\%); zone M sand (28.5\%); OPC (10.5\%) and particulate fine aggregate (7\%).

\subsection{Laser processing arrangement}

In this work a HPDL (DL020, Rofin-Baasel) emitting at $940 \pm 10 \mathrm{~nm}$ with a maximum output power of $2 \mathrm{~kW}$. The HPDL beam was delivered to the work area by means of a $10 \mathrm{~m}$ long, $1.5 \mathrm{~mm}$ core diameter optical fibre, the end of which was connected to a focusing lens assembly. The laser operated in the continuous wave $(\mathrm{CW})$ mode and produced a multi-mode beam. The defocused laser beam was fired across the surface of the OPC samples by traversing the samples beneath the beams using the $\mathrm{x}$ - and $\mathrm{y}$-axis of CNC gantry tables at speeds ranging from $60-600 \mathrm{~mm} / \mathrm{min}$. The laser optics were protected by means of a coaxially blown shield gas jet a rate of $5 \mathrm{1} / \mathrm{min}$. To investigate the effects of process gas type $\mathrm{Ar}, \mathrm{N}_{2}$ and $\mathrm{O}_{2}$ process gasses were employed. To determine the characteristics of the glazes the as-received and HPDL treated OPC samples were examined using optical microscopy, scanning electron microscopy (SEM), energy disperse X-ray analysis (EDX) and $\mathrm{X}$-ray diffraction $(\mathrm{XRD})$ techniques.

\subsection{Wetting and surface energy characterisation procedure}

To examine the wetting and surface energy characteristics of the as-received and HPDL treated OPC and hence quantify any surface energy changes in the OPC resulting from HPDL interaction, a series of control experiments were carried out using the sessile drop technique with a variety of liquids with known surface energy properties. The control test liquids, along with their total surface energy, dispersive and polar components, are detailed in Table 1. This particular test liquid series was selected because it has been shown in previous studies $[34-38,48]$ to be most suitable for materials such as OPC. The experiments were conducted in normal atmospheric conditions at a temperature of $20^{\circ} \mathrm{C}$ $\pm 2^{0} \mathrm{C}$ with the temperature of the liquids themselves throughout the experiments also being maintained at around $20^{\circ} \mathrm{C}$. The droplets were released onto the surface of the test OPC (HPDL treated and as-received) from the tip of a micropipette, with the resultant volume of the drops being approximately $6 \times 10^{-3} \mathrm{~cm}^{3}$. Each experiment lasted for three minutes and profile photographs of the 
sessile drops being obtained every minute with $\theta$ being measured simultaneously. The standard deviation due to experimental error was calculated as being $\pm 0.8^{0}$.

\section{The effects of high power diode laser interaction on the wettability characteristics of ordinary Portland cement}

An optical micrograph of a sessile drop of a solidified vitreous enamel $\left(20^{\circ} \mathrm{C}\right)$ placed on the surface of the OPC (a) before and (b) after HPDL irradiation with $\theta$ superimposed is shown in Fig. 1. The experimental results showed that throughout the period of cooling of the enamel, from the molten state at $600^{\circ} \mathrm{C}$ to the solid state at room temperature, no discernible change in the magnitude of the of $\theta$ took place during the time of the experiments. This observation indicates that thermodynamic equilibrium was established at the solid-liquid interface at the outset of the experiment [48]. It is clearly apparent from Fig. 1 that prior to HPDL interaction, it was not possible to fire the enamel onto the surface of the OPC since $\theta$ was measured as $109^{\circ}$, and as such would prevent the enamel from wetting the OPC. Indeed, HPDL interaction with the enamel when placed on the as-received OPC surface simply resulted in the 'balling' of the enamel, that is the formation of small spheres approximately the diameter of the laser beam itself [49-50]. Furthermore, as is evident from Table 2, under the experimental laser parameters employed and processing in an $\mathrm{O}_{2}$ atmosphere, HPDL irradiation of the surface of the OPC samples resulted in changes in $\theta$. It can be seen that in general, interaction of the OPC with the HPDL beam resulted in the $\theta$ between the OPC and the control liquids reducing.

\subsection{The effect of surface morphology}

The role that the morphology of HPDL treated OPC surface plays in influencing wetting characteristics is of some importance. More specifically, the aspect of the surface morphology that is of particular importance is substrate surface roughness, since this aspect contributes to effect changes in $\theta$. Rough grooves on a surface can be categorised as either radial or circular grooves. In practical terms, any rough surface can be represented by a combination of these two cases [51], with two roughness parameters being defined as the Wenzel type, $D_{R}[52]$ and the Cassie/Baxter type, $F_{R}[53]$. In the case that wetting spreads radially, as is the likely case with the OPC, then the resulting radial contact angle, $\theta_{\text {rad }}$, is related to the theoretical contact angle, $\theta_{t h}$, by [51]

$$
\cos \theta_{\text {rad }}=D_{R}\left(1-F_{R}\right) \cos \theta_{t h}-F_{R}
$$

According to Neumann [54], only if $F_{R}$ is equal to zero, then a model similar to that for heterogeneous solid surfaces can be developed in order to account for surface irregularities, being given by a rearrangement of Wenzel's equation: 


$$
\gamma_{s l}=\gamma_{s v}-\left(\frac{\gamma_{l v} \cos \theta_{w}}{r}\right)
$$

where, $r$ is the roughness factor defined as the ratio of the real and apparent surface areas and $\theta_{w}$ is the contact angle for the wetting of a rough surface. It is important to note that Wenzel's treatment is only effective at the position of wetting triple line [52]. Nonetheless, it is evident from Eq. (15) that if the roughness factor, $r$, is large, that is the solid surface is smooth, then $\gamma_{\mathrm{sl}}$ will become small, thus, a reduction in the contact angle will be inherently realised by the liquid if $\theta_{w}<90^{\circ}$. Conversely, if $\theta_{w}>90^{\circ}$ then the opposite will be observed. At this point it is worth remarking that other more sophisticated approaches may be taken to examine the effects of surface roughness on wetting [55]. For this present study, however, the use of Eq. (7) is quite sufficient.

Regardless of the process gas used, marked reductions in the surface roughness of the OPC were observed (using a Taylor-Hobson Surtronic 3+ profileometer) after interaction with the HPDL beam (see Table 3). Therefore, according to Eq. (3), a reduction in $\theta$ will be inherently effected. Indeed, this presumption appears to be valid when one considers the $\theta$ values observed for the various control liquids in contact with the HPDL treated OPC (see Table 2). Such results are in agreement with those obtained by Nicolas et al. [56] and Lawrence et al.[34-38], who observed that laser treatment of various ceramic materials yielded smoother surfaces.

\subsection{The effect of process gas type}

According to Ueki [57] and $\mathrm{Li}$ [58], process gas type will play a part in determining $\theta$, since the $\mathrm{O}_{2}$ content of a material's surface is an influential factor governing the wetting performance of the material. Experiments were therefore conducted to investigate the effects of using $\mathrm{Ar}, \mathrm{N}_{2}$ and $\mathrm{O}_{2}$ process gasses on $\theta$. In order to study exclusively the effects of process gas on the wettability characteristics of the OPC, the HPDL operating parameters were set such that a similar degree of melting and solidification occurred and a similar surface roughness was achieved. Wetting is governed by the first atomic layers of the surface of a material, so to determine the element content of $\mathrm{O}_{2}$ at the surface of the OPC, it was necessary to examine the surface using X-ray photoemission spectroscopy (XPS).

The results of the XPS analysis of the OPC in terms of the surface $\mathrm{O}_{2}$ content when processed with the selected gasses is shown in Fig. 2. As is evident from Fig. 2, increases in the surface $\mathrm{O}_{2}$ content of the OPC after HPDL interaction were observed only when processing was carried with an $\mathrm{O}_{2}$ processing gas; in all other instances the surface $\mathrm{O}_{2}$ content remained similar to the original value. More significantly, the assertion that surface $\mathrm{O}_{2}$ content is an important factor in determining $\theta$ is confirmed somewhat by Fig. 3, in which the effects of the differences in surface $\mathrm{O}_{2}$ content appear to have a noticeable influence on $\theta$. Yet it is highly significant that the reductions in $\theta$ seen in Fig. 5 bear 
no direct relationship with the surface $\mathrm{O}_{2}$ content results given in Fig. 4. Indeed, Fig. 5 shows that reductions in $\theta$ were brought about after HPDL treatment regardless of the process gas employed, with the reductions being similar in value. Nevertheless, Fig. 5 shows quite clearly that the largest reduction in $\theta$ occurred when $\mathrm{O}_{2}$ was used as the process gas and the surface $\mathrm{O}_{2}$ content was subsequently the highest.

\subsection{The effect of surface energy and its dispersive/polar attributes}

As was mentioned earlier in Section 2, the dispersive component of the surface energy of the OPC can be estimated by using Eq. (7) and plotting the graph of $\cos \theta$ against $\left(\gamma_{l v}^{d}\right)^{1 / 2} / \gamma_{l v}$. Thus, Fig. 4 shows the best-fit plot of $\cos \theta$ against $\left(\gamma_{l v}^{d}\right)^{1 / 2} / \gamma_{\mathrm{lv}}$ according to Eq. (7) for the as-received and HPDL treated OPC (Ar, $\mathrm{N}_{2}$ and $\mathrm{O}_{2}$ process gas) - experimental control liquids system. Comparing the ordinate intercept points of the as-received and HPDL treated $\mathrm{OPC}\left(\mathrm{Ar}, \mathrm{N}_{2}\right.$ and $\mathrm{O}_{2}$ process gas) - liquid systems, it can be seen clearly from Fig. 4 that for the as-received OPC ( $\mathrm{Ar}, \mathrm{N}_{2}$ and $\mathrm{O}_{2}$ process gas) liquid systems the best-fit straight line intercepts the ordinate closer to the origin, indicating that, in principle, dispersion forces act mainly at the as-received OPC - liquid interfaces resulting in poor adhesion $[45,59]$. Conversely, Fig. 4 shows that the best-fit straight line for the HPDL treated OPC (Ar, $\mathrm{N}_{2}$ and $\mathrm{O}_{2}$ process gas) - liquid systems intercepts the ordinate much higher above the origin. Such a finding implies the action of polar forces across the interface, in addition to dispersion forces, therefore improved wettability and adhesion is promoted [45, 59].

Now, earlier in Section 2 it was shown that it is not possible to determine the value of $\gamma_{s v}^{p}$ for the OPC directly from Fig. 4. Instead it is necessary to utilise Eq. (13). But first it is a prerequisite that that values of the constants $a$ and $c$ are determined. So, plotting according to Eq. (10) yielded a linear relationship between $\gamma_{s v}^{d}$ and $\gamma_{s v}^{p}$ for the control test liquids used. Thus the value of $c$ was deduced as 1.3. Similarly, plotting according to Eq. (11) for the as-received and HPDL treated OPC (Ar, $\mathrm{N}_{2}$ and $\mathrm{O}_{2}$ process gases) allowed $a$ to be determined

The values determined for $\gamma_{s v}^{d}$ and $\gamma_{s v}^{p}$ for both the as-received and HPDL treated OPC (Ar, $\mathrm{N}_{2}$ and $\mathrm{O}_{2}$ process gas) are given in Table 4. Evidently the HPDL treatment of the surface of the OPC, in any gas atmosphere, leads to an increase in the total surface energy whilst increasing $\gamma_{s v}^{p}$, thereby improving the action of wetting and adhesion. Such changes in the surface energy of the OPC after HPDL treatment are due to the fact that partial vitrification of the surface is occasioned, a transition that is known to effect a reduction in $\gamma_{s v}$ and an increase in $\gamma_{s v}^{p}$ [48]. It is important to note that because of the long range ionic interactions in the OPC and the composite nature of the interfaces between the OPC and the liquids, it is highly likely that the thermodynamically defined total solid surface energy, as defined in Eq. (2), will be higher than the sum of the $\gamma^{\mathrm{d}}$ and $\gamma^{\mathrm{p}}$ components of the 
surface energy. Indeed, the derivation that leads to Eq. (5) can only be done under the specific assumption that the ionisation potentials are all equal and that dipole-dipole random orientation interactions dominate over dipole-induced dipole random interactions. Although the increase in (excess) surface free energy will probably be less then the increase in the total lattice energy. On the other hand an absorbed liquid layer may shield the ionic fields substantially. As such, all the data derived from Eqs. (4) - (5) and Eqs. (8) - (12) should be considered as being semi-empirical. Notwithstanding this, as the studies by Gutowski et al. [60] and Agathopoulos and Nikolopoulos [48] found, it is reasonable to conclude from the data obtained from Eqs. (8) - (12) that HPDL treatment of the OPC surface in any gas atmosphere has effected an increase in $\gamma^{\mathrm{p}}$.

\subsection{The effects of surface melting and microstructure}

Owing to its complexity, the chemistry of OPC and the hydration of its various constituents has not yet been fully resolved [61]. Nonetheless, it is known that the constituents of OPC are minerals which exist as multi-component solid solution chemical compounds. One of the major constituents of OPC is $\mathrm{Ca}$, but, OPC contains in relatively large proportions $\mathrm{SiO}_{2}(21 \mathrm{wt} \%), \mathrm{Al}_{2} \mathrm{O}_{3}(5 \mathrm{wt} \%)$ and $\mathrm{Fe}_{2} \mathrm{O}_{3}(3 \mathrm{wt} \%)$, which are basic glass network formers and modifiers. As such, the intense local heating brought about by interaction with the incident HPDL beam results in the melting of these compounds at around $1283^{\circ} \mathrm{C}$, thereby causing the materials to lose the retained water and form an amorphous glaze of glassy material consisting of various calcium-silicate-alumina compounds $[4,15,16]$. Indeed, the amorphous nature of the HPDL generated glaze was verified by an XRD analysis (see Fig. 5). In addition, it is evident from Fig. 6 that the microstructure of the HPDL generated glaze displays no discernible structure and appears to be fully amorphous.

It is worth remarking on the dramatic colour change occasioned in the OPC surface of the concrete after HPDL interaction; changing from grey to green. Such a change can be ascribed to the resultant phase transitions, and also the presence in small concentrations of metal transition ions in various oxidation states within the OPC composition, in particular, ferric ions in the $\mathrm{Fe}^{3+}$ and $\mathrm{Fe}^{2+}$ oxidation state. $\mathrm{Fe}^{3+}$ and $\mathrm{Fe}^{2+}$ ions are known to give rise to green and blue colours respectively when subjected to intense heating [61]. However, if both phases are present within the composition, then the colour is determined by the $\mathrm{Fe}^{3+} / \mathrm{Fe}^{2+}$ ion ratio, resulting in dark blue or black colours [61]. Since the surface produced after HPDL treatment was green, then it is reasonable to assume that both phases were not present within the OPC.

Taken together, it is clear from Fig. 1 that the surface meting and the subsequent changes that are occasioned after interaction with the HPDL beam contribute to the marked effect on $\theta$. Notably, Fig. 1 suggests that the melting, and consequently the vitrification of the glass forming elements $\left(\mathrm{SiO}_{2}\right.$ and $\mathrm{Al}_{2} \mathrm{O}_{3}$ ) within the OPC, is a prerequisite for realising significant reductions in $\theta$. 


\section{Identification of the predominant wettability mechanisms active in the ordinary Portland cement after high power diode laser interaction}

From the foregoing results and discussion it is apparent that interaction of the HPDL beam with the OPC resulted in the $\theta$ formed between the control liquids altering to various degrees, depending upon the laser processing parameters employed, in particular, the processing gas used. These observed changes in the value of $\theta$ are caused by modifications to the wettability characteristics of the OPC and are brought about by: modifications to the surface roughness, changes in the surface $\mathrm{O}_{2}$ content and changes to the surface energy characteristics of the OPC. In the first place, beneficial modifications to the surface roughness of the OPC were seen to occur regardless of the process gas used. This implies that under the conditions used, the HPDL generated glaze on the surface of the OPC gave rise to reductions in the surface roughness, thereby directly reducing $\theta$ in accordance with Eq. (15), and in turn, Eq. (3). Secondly, changes in the surface $\mathrm{O}_{2}$ content of the OPC resulting from HPDL treatment in the various process gas atmospheres is an influential factor in the promotion of the action of wetting. This is because an increase in surface $\mathrm{O}_{2}$ content inherently effects a decrease in $\theta$ and vice versa. Lastly, the melting and resolidification of the surface of the OPC following HPDL interaction occasioned a phase change by generating a vitreous surface. This in turn effected an increase in $\gamma_{s v}^{p}$.

It is not possible to identify from these findings which of these elements of the wettability characteristics of the OPC are active in causing the changes in the wettability characteristics of the OPC after HPDL surface treatment. The degree of influence each element exerts also unclear, as is the question of whether each element acts alone or in association with another. However, by employing a strictly monitored multi-stage grinding procedure, it was possible to isolate the various elements and thus analyse and qualitatively determine the effect each one had on the wettability characteristics of the OPC. In the first stage, the surfaces of the as-received and HPDL treated OPC samples (treated in Ar, $\mathrm{N}_{2}$ and $\mathrm{O}_{2}$ atmospheres) were ground down to a surface roughness (Ra) of $3 \mu \mathrm{m}$, whilst still retaining a HPDL treated surface. In this way it was possible to isolate the effects of surface roughness by rendering them non-effective, and investigate the effects of the microstructural and phase changes (and hence surface energy) and possibly those of the $\mathrm{O}_{2}$ content (and hence process gas effects). In order to evaluate the influence of surface roughness an intermediate grinding stage was incorporated in which the samples were ground down to $1 \mu \mathrm{m}$ whilst still retaining the HPDL induced microstructure. In the final stage the same OPC samples were ground down further $(1 \mu \mathrm{m})$ to remove the HPDL induced microstructures. In this way one is effectively removing the effects of microstructural changes (surface energy) from the previous investigation, thereby allowing the $\mathrm{O}_{2}$ content (process gas effects) to be studied. 
An examination of the $\theta$ characteristics of the ground OPC samples using only glycerol revealed that a considerable difference in $\theta$ between the HPDL treated and as-received samples was still present. For the HPDL treated samples, $\theta$ had increased slightly across the range of samples to around $26-29^{0}$. In contrast, $\theta$ for the as-received samples was seen to have reduced from $40^{\circ}$ to $37^{\circ}$. From an XPS analysis of the $\mathrm{O}_{2}$ content of the OPC samples it was found that the $\mathrm{O}_{2}$ content of the as-received sample remained around the original value of $44.7 \mathrm{at} \%$, whilst that of the HPDL treated samples was found to have reduced to a level similar to that of the as-received sample, 44.9-45.2at\%. Since a considerable difference in the measured $\theta$ of the HPDL treated and as-received OPC samples was still in evidence, despite grinding down the samples to a surface roughness of $3 \mu \mathrm{m}$, is it is reasonable to postulate that surface roughness does not have as greater influence on the wetting characteristics of the OPC as microstructure. The slight increase in $\theta$ for the HPDL treated OPC samples is believed to be due to the reduction on the surface $\mathrm{O}_{2}$ content. This is noteworthy as such a supposition implies that surface $\mathrm{O}_{2}$ content is more influential in determining the wetting characteristics of the OPC than surface roughness. Indeed, additional grinding of the samples bore this assertion out somewhat. In this subsequent stage the samples were ground down to a surface roughness of $1 \mu \mathrm{m}$ whilst still retaining the HPDL induced microstructure, thereby allowing a comparative analysis of the effects of surface $\mathrm{O}_{2}$ content and surface roughness to be carried out. An XPS analysis of the $\mathrm{O}_{2}$ content of the OPC samples revealed that the $\mathrm{O}_{2}$ content of the as-received and HPDL treated samples remained around the values obtained after the first grinding stage; for the as-received sample around the original value of $44.7 \mathrm{at} \%$ and likewise for the HPDL treated samples at $45.0-45.4 \mathrm{at} \%$. The values of $\theta$ observed for the as-received and HPDL treated OPC were again markedly different. Whereas in the previous grinding stage, $\theta$ for the HPDL treated samples remained consistent at $27-29^{\circ}$, for the as-received samples $\theta$ had further reduced to $35^{\circ}$. Following on from this observation it is possible to assert that the reductions in $\theta$ due to reductions in the surface roughness are limited to a value well above that achieved after HPDL treatment. Moreover, this leads one to conclude that surface $\mathrm{O}_{2}$ content is indeed more instrumental in deciding the wetting characteristics of the OPC than surface roughness since no reduction in $\theta$ for the HPDL treated OPC samples was observed after generating a much smoother surface. After the same OPC samples were ground down further $(1 \mu \mathrm{m})$ to remove the HPDL induced microstructures, an XPS analysis showed that the surface $\mathrm{O}_{2}$ content on the as-received and HPDL treated samples were virtually the same value as the original as-received sample, 44.6-44.8at\%. Similarly, an examination of the contact angles for the as-received and HPDL treated samples revealed that $\theta$ for the as-received OPC sample remained at approximately the same value as in the previous grinding stage, $35^{\circ}$. But more significantly, $\theta$ for the HPDL treated samples had increased and was now consistently in the region of the as-received samples, $36-38^{0}$. Clearly the removal of the HPDL generated microstructure has effected an increase in $\theta$ for the HPDL treated samples, despite 
the generation of a much smoother surface $(1 \mu \mathrm{m}$ compared to 2.9-3.8 $\mu \mathrm{m})$. Such findings reveal unequivocally that microstructure is by far the most predominant mechanism governing the wetting characteristics of the OPC. So, it is therefore reasonable to assume that surface energy differences brought about by microstructural changes have a more active part in deciding the wettability characteristics of the OPC than either surface roughness or surface $\mathrm{O}_{2}$ content. Furthermore, because a $\theta$ increase, rather than a decrease, was realised for the HPDL treated OPC samples when reductions in the surface $\mathrm{O}_{2}$ were occasioned and smoother surfaces were generated simultaneously, it is reasonable to assume that $\mathrm{O}_{2}$ has more influence over the wettability characteristics of the OPC than surface roughness.

\section{Conclusions}

High power diode laser (HPDL) modification of the contact angle, $\theta$, and hence the wettability characteristics of OPC has been demonstrated. Such changes in the wettability characteristics of the OPC after HPDL treatment can be attributed to: modifications to the surface roughness which accordingly effected reductions in $\theta$; the increase in the surface $\mathrm{O}_{2}$ content of the OPC which intrinsically brings about a decrease in $\theta$, and vice versa and the semi-empirically determined increase in the polar component of the surface energy, $\gamma_{s v}^{p}$, of the OPC due to the HPDL induced surface melting and resolidification which consequently created a vitrified microstructure that was seen to augment the wetting action. Work was conducted to isolate each of these elements, thereby allowing the magnitude of their influence to be qualitatively determined. The degree of influence exerted by each element was found to differ considerably. From the analysis, surface energy, by way of microstructural and phase changes, was found to be by far the most predominant element active. To a much lesser extent, surface $\mathrm{O}_{2}$ content, by way of process gas, was also seen to contribute to effecting changes in the wettability characteristics of the OPC, whilst surface roughness was found to play a minor role in inducing changes in the wettability characteristics. Furthermore, based on the findings of this study, it is not unreasonable to assert that the results are generic and could therefore be applied to many ceramic materials of a similar nature in terms of wettability characteristics modification by means of HPDL radiation. 


\section{References}

1. K. Sugita, M. Mori, T. Fujioka, Concrete Eng. 24 (1986) 13-22.

2. M. Hamasaki, Proceedings of The International Symposium on Laser Processing, San Jose, May 1987, pp. 158-167.

3. H. Yoshizawa, S. Wignarajah, H. Saito, Trans. Japan Welding Soc. 20 (1989) 31-36.

4. L. Li, P.J. Modern, W.M. Steen, Proceedings of LAMP '92: Science and Applications, Nagaoka, June 1992, (High Temperature Society of Japan, Osaka, 1993), pp. 843-848.

5. L. Li, W.M. Steen, P.J. Modern, Proceedings of ISLOE '93, Singapore, November 1993, (National University of Singapore, Singapore, 1994), pp. 25-30.

6. L. Li, W.M. Steen, P.J. Modern, J.T. Spencer, Proceedings of RECOD '94, London, April 1994, (SPIE, Bellingham, 1994), pp. 24-28.

7. L. Li, W.M. Steen, P.J. Modern, J.T. Spencer, Proceedings of EUROPTO '94: Laser Materials Processing and Machining, Frankfurt, June 1994, (SPIE, Bellingham, WA, 1994), pp. 84-95.

8. E.P. Johnston, G. Shannon, W.M. Steen, D.R. Jones, J.T. Spencer, Proceedings of ICALEO '98: Laser Materials Processing, November 1998, Orlando, Vol 85E, (Laser Institute of America, Orlando, 1999), pp. 210-218.

9. K. Sugimoto, S. Wignarajah, K. Nagasi, S. Yasu, Proceedings of ICALEO '90: Laser Materials Processing, Boston, November 1990 , (Laser Institute of America, Orlando, 1991), pp. 302-312.

10. S. Wignarajah, K. Sugimoto, K. Nagai, Proceedings of ICALEO '92: Laser Materials Processing, Orlando, October 1992, (Laser Institute of America, Orlando, 1993), pp. 383-393.

11. T.I. Borodina, G.E. Valyano, N.I. Ibragimov, E.P. Pakhomov, A.I. Romanov, L.G. Smirnova, P.K. Khabibulaev, J. Phys. Chem. Mater. Treatment 25 (1995) 541-546.

12. L. Li, J. Lawrence, J.T. Spencer, Proceedings of SPIE: Europto'97 Lasers in Material Processing, Munich, June 1997, Vol 3097, (SPIE, Bellingham, WA, 1997), pp. 600-611.

13. J. Lawrence, L. Li, Proceedings of ICALEO '99: Laser Materials Processing, San Diego, CA, November 1999, Vol 86D, (Laser Institute of America, Orlando, 1993), pp. 334-353.

14. J. Lawrence, L. Li, Optics Laser Tech. 31 (1999) 583-591.

15. J. Lawrence, L. Li, Mater. Sci. Eng A. 284 (2000) 93-102.

16. J. Lawrence, L. Li, J. of Laser Apps. 12 (2000) 116-125.

17. J. Lawrence, L. Li, Mater. Sci. Eng. A. 287 (2000) 25-29.

18. J. Lawrence, L. Li, Appl. Surf. Sci. 168 (2000) 25-28.

19. X.B. Zhou, J.T.M. DeHosson, J. de Phys. IV 3 (1993) 1007-1011.

20. X.B. Zhou, J.T.M. DeHosson, Acta Metall. Mater. 42 (1994) 1155-1162. 
21. T. Bahners, Opt. Quan. Elec. 27 (1993) 1337-1348.

22. T. Bahners, W. Kesting, E. Schollmeyer, 1993 Appl. Surf. Sci. 69 (1993) 12-15.

23. J. Heitz, E. Arenholz, T. Kefer, D. Bäuerle, H. Hibst, A. Hagemeyer, Appl. Phys. A 55 (1992) 391-392.

24. H. Watanabe, H. Shimizu, T. Takata, Sen'-i Gakkaishi 49 (1993) 616-623.

25. J.E. Andrew, P.E. Dyer, D. Forster, P.H. Key, Appl. Phys. Lett. 43 (1983) 717-718.

26. H. Watanabe, T. Takata, J. Adhesion Sci. Tech. 8 (1994) 1425-1438.

27. P. Laurens, B. Sadras, F. Decobert, F. Arefiknonsari, J. Amouroux, Int. J. Adhesion Adhesives 18 (1998) 19-27.

28. P. Laurens, B. Ould Bouali, F. Meducin, B. Sadras, Appl. Surf. Sci. 154/155 (2000) 658-663.

29. Q. Song, A.N. Netravali, J. Adhesion Sci. Tech. 9 (1998) 957-982.

30. Q. Song, A.N. Netravali, J. Adhesion Sci. Tech. 9 (1998) 983-998.

31. Q. Song, A.N. Netravali, J. Adhesion Sci. Tech. 13 (1999) 501-516.

32. F Henari, W. Blau, Appl. Optics 34 (1995) 581-584.

33. M. Olfert, W. Duley, T. North, in: J. Mazumder, O. Conde, R. Villan \& W. M. Steen (Eds.), Laser Processing, Kluwer Academic Publishers, 1996, pp. 479-490.

34. J. Lawrence, L. Li, J.T. Spencer, Optics Laser Tech. 30 (1998) 205-214.

35. J. Lawrence, L. Li, Appl. Surf. Sci. 138/139 (1999) 388-393.

36. J. Lawrence, L. Li, J. Phys. D. 32 (1999) 1075-1082.

37. J. Lawrence, L. Li, Mater. Sci. Eng. A. 266 (1999) 1067-1074.

38. J. Lawrence, L. Li, J.T. Spencer, Surf. Coatings Tech. 115 (1999) 273-281.

39. J. Lawrence, L. Li, J. Phys. D. 32 (1999) 2311-2318.

40. J. Lawrence, L. Li, Optics Lasers Eng. 32 (1999) 353-365.

41. J. Lawrence, L. Li, Appl. Surf. Sci. 154/155 (2000) 664-669.

42. J. Lawrence, L. Li, Mater. Sci. Eng. A. 303 (2001) 142-149.

43. J. Lawrence, L. Li, J. Eng. Manuf. 215 (2001) 1735-1744.

44. J. Lawrence, L. Li, J. Laser App. 14 (2002) 107-113.

45. F.M. Fowkes, 1964 Ind. Eng. Chem. 56 (1964) 40-52.

46. W.A. Zisman, in: R.F. Gould (Ed.) in: Advances in Chemistry Series 43 (Ed.), American Chemical Society, Washington DC, 1964, pp 1-51.

47. R.J. Good, L.A. Girifalco, J. Phys. Chem. 64 (1960) 561-565.

48. S. Agathopoulos, P. Nikolopoulos, J. of Biomed. Mater. Res. 29 (1995) 421-429. 
49. D.L. Bourell, H.L. Marcus, J.W. Barlow, J.J. Beaman, Int. J. Powder Metall. 28 (1992) 369-381.

50. M. Agarwala, D.L. Bourell, J.J. Beaman, H.L. Marcus, J.W. Barlow, Rapid Prototyping J. 1 (1995) 26-36.

51. X.B. Zhou, J.T.M. DeHosson, J. Mat. Research 10 (1995) 1984-1992.

52. R.N. Wenzel, Ind. Eng. Chem. 28 (1936) 988- 994.

53. A.B.D. Cassie, S. Baxter, Trans. Faraday Soc. 40 (1944) 546-552.

54. A.W. Neumann, Adv. Colloid Interface Sci. 4 (1974) 438.

55. G. Palasantzas, J.T.M. DeHosson, Acta Mater. 49 (2001) 3533-3538.

56. G. Nicolas, M. Autric, W. Marine, G.A. Shafeev, Appl. Surf. Sci. 109/110 (1997) 289-292.

57. M. Ueki, M. Naka, I. Okamoto, J. Mater. Sci. Lett. 5 (1986) 1261-1262.

58. J.G. Li, Mater. Lett. 22 (1995) 169-174.

59. D.K. Chattoraj, K.S. Birdi, Adsorption and the Gibbs Surface Excess, Plenum Press, New York, 1984.

60. W.W. Gutowski, L. Russell, A. Cerra, in: J.M. Klosowski (Ed.), Science and Technology of Building Seals, Sealants, Glazing and Waterproofing, ASTM, Philadelphia, 1992, pp 144-159.

61. G.D. Taylor, Construction Materials, Longman Scientific \& Technical, London, 1991, pp. 31-34. 


\section{List of Figures}

Fig. 1. Contact angles for the enamel on (a) the as-received surface of the OPC and (b) the HPDL treated surface of the OPC.

Fig. 2. Surface $\mathrm{O}_{2}$ content of the OPC before and after HPDL surface treatment in the various process gas environments $\left(2.25 \mathrm{~kW} / \mathrm{cm}^{2}\right.$ laser power density and $240 \mathrm{~mm} / \mathrm{min}$ traverse speed).

Fig. 3. Mean values of $\theta$ formed between glycerol at $20^{\circ} \mathrm{C}$ and the OPC before and after HPDL surface treatment in the various process gas environments $\left(2.25 \mathrm{~kW} / \mathrm{cm}^{2}\right.$ laser power density and 240 $\mathrm{mm} / \mathrm{min}$ traverse speed).

Fig. 4. Plot of $\cos \theta$ against $\left(\gamma_{l v}^{d}\right)^{1 / 2} / \gamma_{l v}$ for the OPC before and after HPDL surface treatment in the various process gas environments in contact with the wetting test control liquids.

Fig. 5. XRD analysis of the OPC surface (a) before laser treatment and (b) after HPDL treatment $\left(2.25 \mathrm{~kW} / \mathrm{cm}^{2}\right.$ laser power density, $240 \mathrm{~mm} / \mathrm{min}$ traverse speed and $\mathrm{O}_{2}$ processing gas).

Fig. 6. Typical SEM micrograph of the fracture section of the OPC surface glaze generated with the HPDL. (2.25 kW/ $\mathrm{cm}^{2}$ laser power density, $240 \mathrm{~mm} / \mathrm{min}$ traverse speed and $\mathrm{O}_{2}$ processing gas) 
Fig. 1

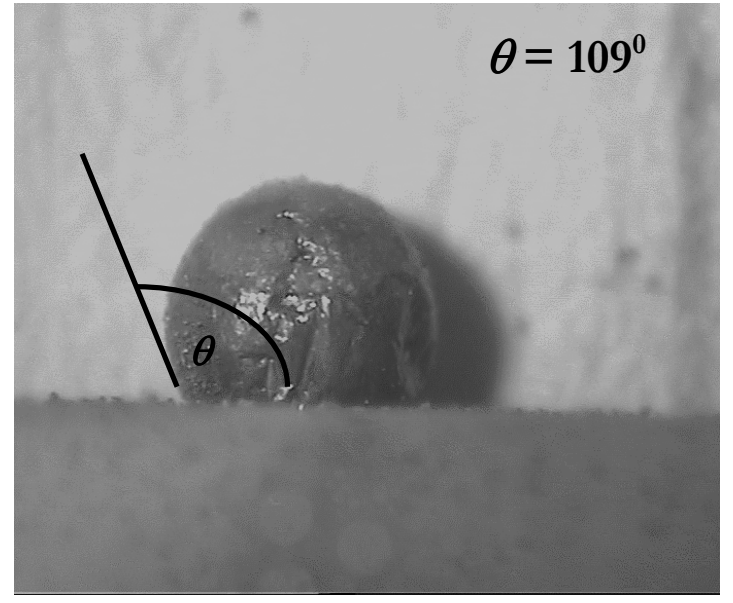

(a)

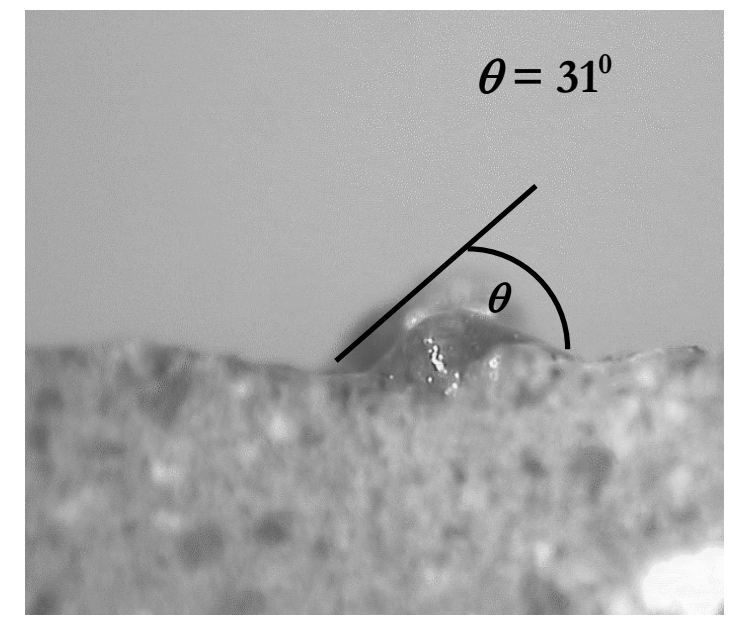

(b) 
Fig 2

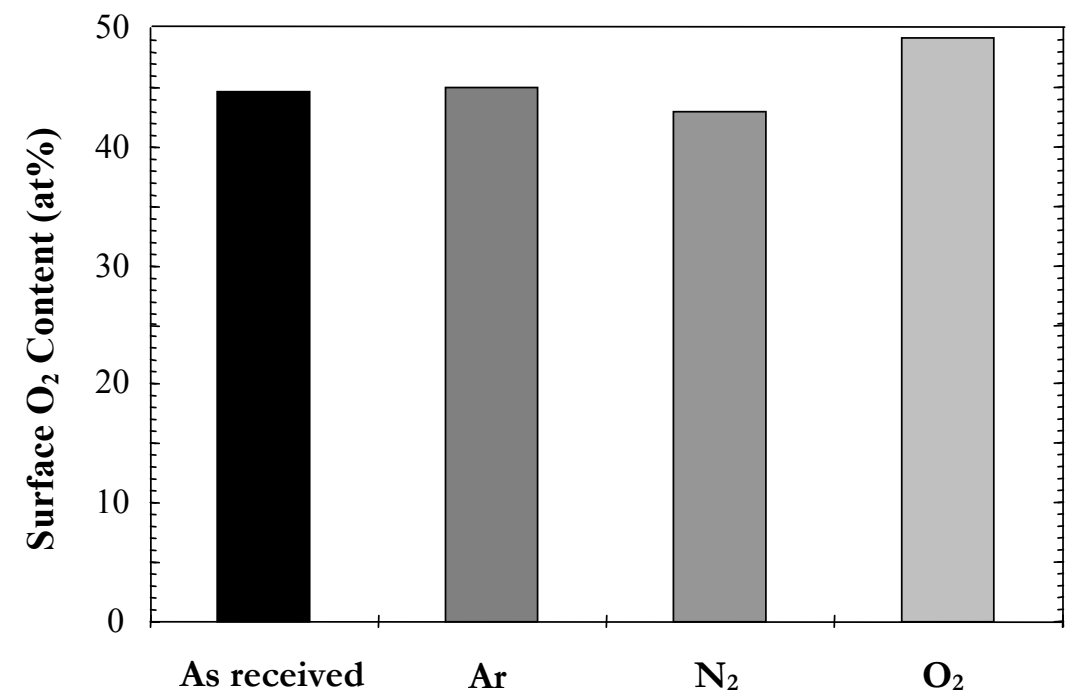


$\underline{\text { Fig } 3}$

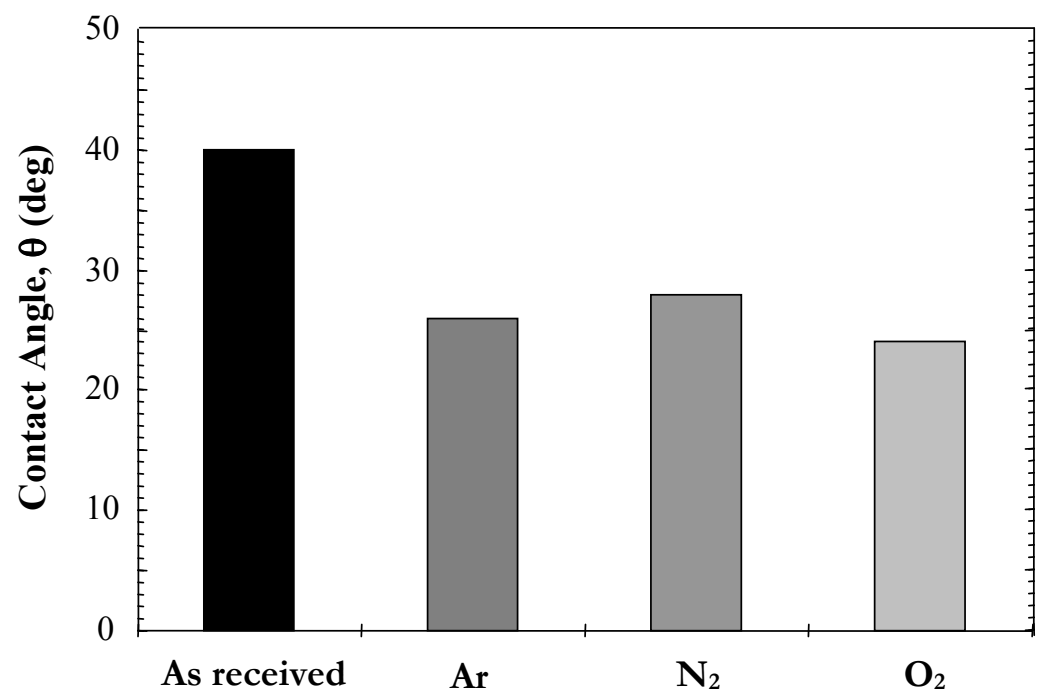




\section{Fig 4}

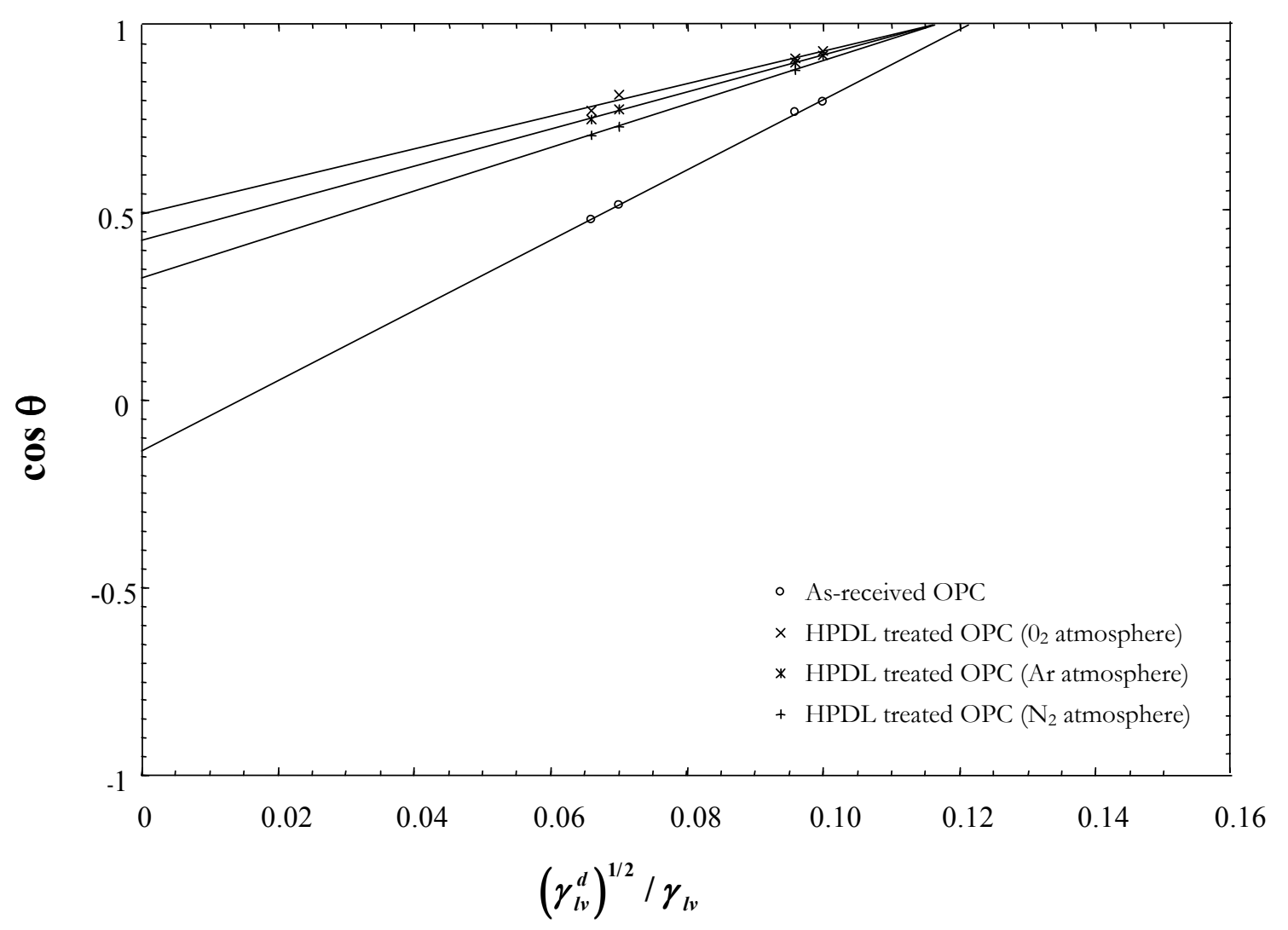


Fig. 5

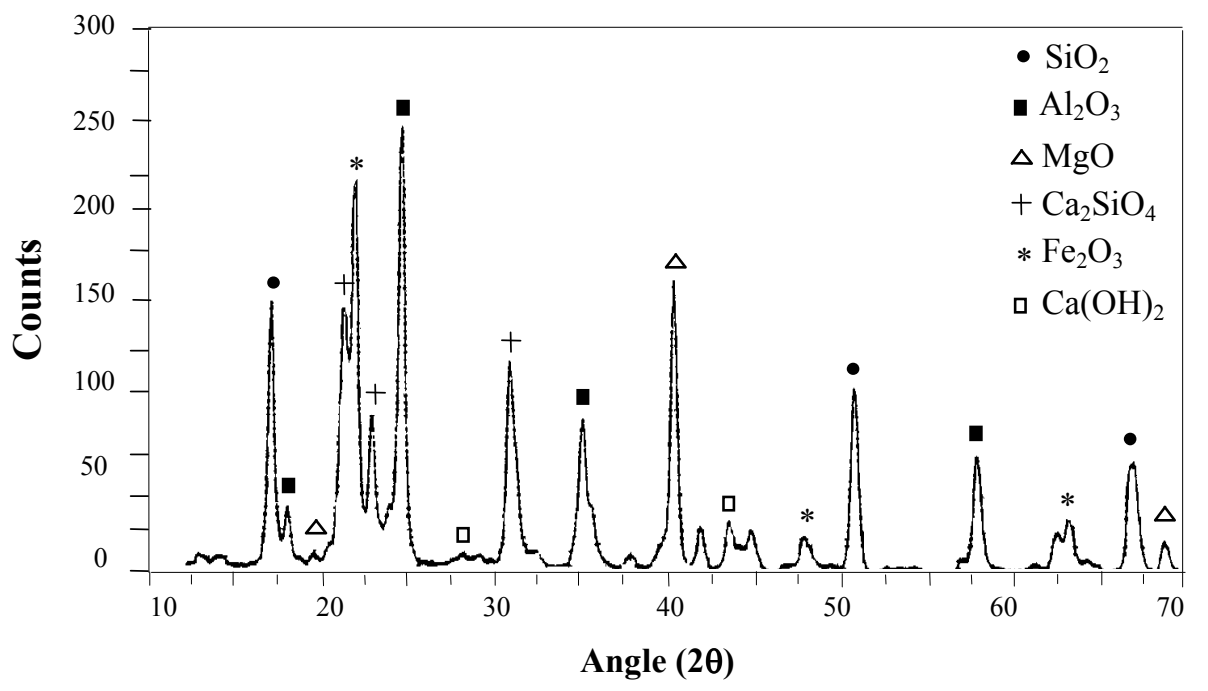

(a)

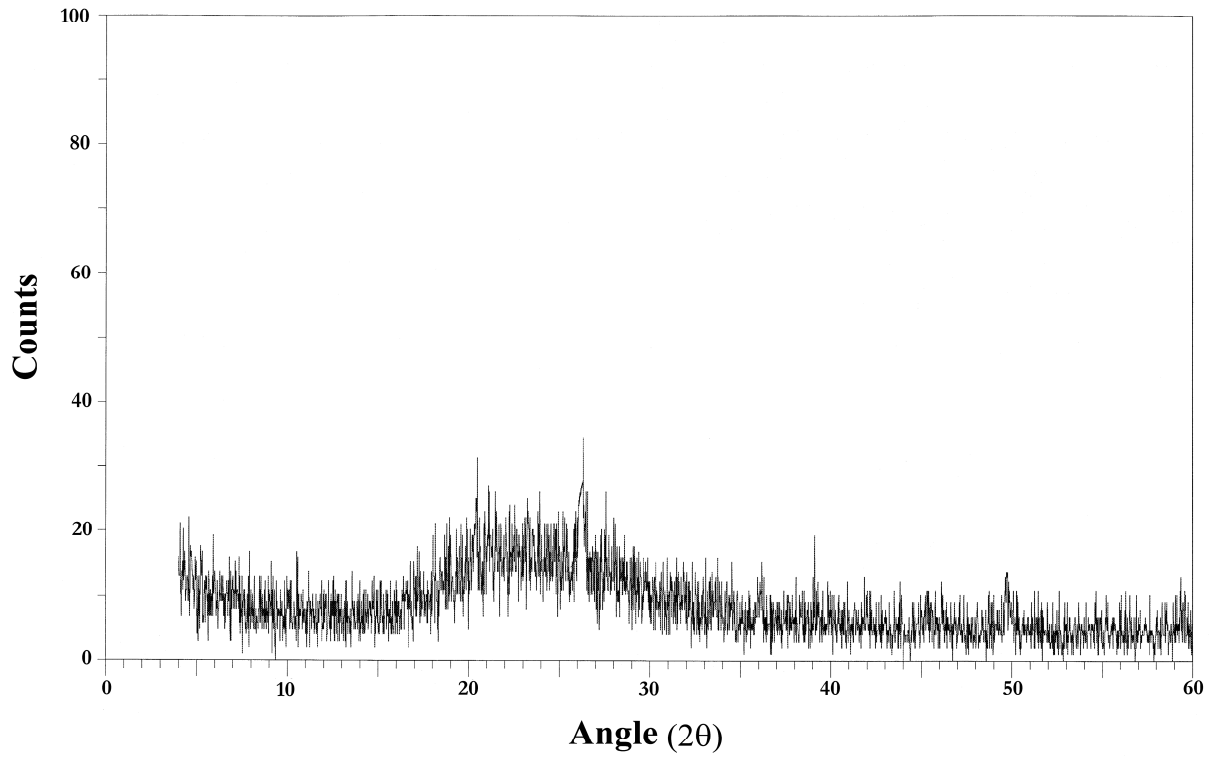

(b) 
Fig. 6

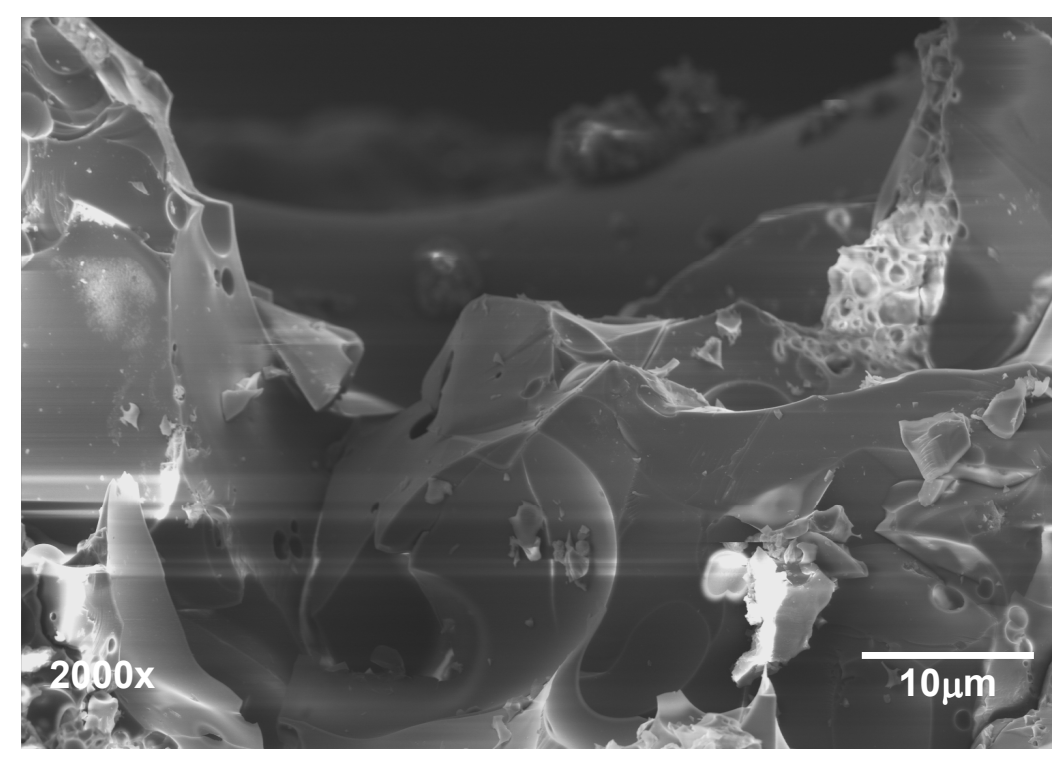




\section{$\underline{\text { List of Tables }}$}

Table 1. Total surface energy $\left(\gamma_{\mathrm{lv}}\right)$ and the dispersive $\left(\gamma_{l v}^{d}\right)$ and polar $\left(\gamma_{l v}^{p}\right)$ components for the selected test liquids [34].

Table 2. Mean values of $\theta$ formed between the selected control test liquids at $20^{\circ} \mathrm{C}$ and the OPC before and after HPDL surface treatment in the various process gas environments $(40 \mathrm{~W}$ laser power, $1500 \mathrm{~mm} / \mathrm{min}$ traverse speed).

Table 3. Surface roughness values $(\mathrm{Ra})$ of the OPC before and after interaction with the HPDL in the various process gas environments (40 W laser power and $1500 \mathrm{~mm} / \mathrm{min}$ traverse speed).

Table 4. Measured surface energy values for the OPC before and after HPDL irradiation in the various process gas environments ( $40 \mathrm{~W}$ laser power and $1500 \mathrm{~mm} / \mathrm{min}$ traverse speed). 


\section{Table 1}

\begin{tabular}{lccc}
\hline Liquid & $\begin{array}{c}\gamma \\
\left(\mathbf{m J} / \mathbf{m}^{2}\right)\end{array}$ & $\begin{array}{c}\gamma_{l v}^{d} \\
\left(\mathbf{m J} / \mathbf{m}^{2}\right)\end{array}$ & $\begin{array}{c}\gamma_{l v}^{p} \\
\left(\mathbf{m J} / \mathbf{m}^{2}\right)\end{array}$ \\
\hline Human Blood & 47.5 & 11.2 & 36.3 \\
Human Blood Plasma & 50.5 & 11.0 & 39.5 \\
Glycerol & 63.4 & 37.0 & 26.4 \\
4-Octonol & 27.5 & 7.4 & 20.1 \\
\hline
\end{tabular}




\section{Table 2}

\begin{tabular}{lcccc}
\hline \multirow{2}{*}{ Control Test Liquid } & \multicolumn{4}{c}{ Contact Angle, $\boldsymbol{\theta}(\mathbf{d e g})$} \\
\cline { 2 - 5 } & As-received & \multicolumn{3}{c}{ HPDL Treated } \\
\cline { 2 - 5 } & & Ar Process Gas & $\mathbf{N}_{\mathbf{2}}$ Process Gas & $\mathbf{O}_{\mathbf{2}}$ Process Gas \\
\hline Human Blood Plasma & 61 & 42 & 45 & 41 \\
Human Blood & 58 & 38 & 43 & 35 \\
Glycerol & 40 & 26 & 28 & 24 \\
4-Octonol & 37 & 23 & 25 & 21 \\
\hline
\end{tabular}


$\underline{\text { Table } 3}$

Surface Roughness, Ra $(\mu \mathrm{m})$

\begin{tabular}{cccc}
\hline As-received & $\mathrm{Ar}$ & $\mathrm{N}_{2}$ & $\mathrm{O}_{2}$ \\
\hline 21.9 & 3.8 & 3.1 & 2.9 \\
\hline
\end{tabular}




\section{Table 4}

\begin{tabular}{lcccc}
\hline Surface Energy Component & As-received & \multicolumn{3}{c}{ HPDL Treated } \\
\cline { 3 - 4 } & & Ar Process Gas & N$_{\mathbf{2}}$ Process Gas & O Process Gas \\
\hline Dispersive Component $\left(\gamma_{s v}^{d}\right)$ & $65.0 \mathrm{~mJ} / \mathrm{m}^{2}$ & $72.6 \mathrm{~mJ} / \mathrm{m}^{2}$ & $72.5 \mathrm{~mJ} / \mathrm{m}^{2}$ & $73.1 \mathrm{~mJ} / \mathrm{m}^{2}$ \\
Polar Component $\left(\gamma_{s v}^{p}\right)$ & $3.5 \mathrm{~mJ} / \mathrm{m}^{2}$ & $11.9 \mathrm{~mJ} / \mathrm{m}^{2}$ & $9.4 \mathrm{~mJ} / \mathrm{m}^{2}$ & $15.6 \mathrm{~mJ} / \mathrm{m}^{2}$ \\
Total Surface Energy $\left(\gamma_{s v}\right)$ & $68.5 \mathrm{~mJ} / \mathrm{m}^{2}$ & $84.5 \mathrm{~mJ} / \mathrm{m}^{2}$ & $81.9 \mathrm{~mJ} / \mathrm{m}^{2}$ & $88.7 \mathrm{~mJ} / \mathrm{m}^{2}$ \\
\hline
\end{tabular}

